\title{
Study of Specific Learning Disorder in Children with Poor Academic Performers
}

\author{
Dr. Jitendra Mugali ${ }^{1}$, Dr. Sandeep Patil ${ }^{2}$, Dr. Kaustubh Gosavi ${ }^{3}$, Dr. Nitin \\ Pattanshetti ${ }^{4}$, Dr. Sritha Kovvuri ${ }^{5}$, Dr. Deepthi P.T ${ }^{6}$
}

\section{ABSTRACT}

Objectives: To study the nature and prevalence of specific learning disorder in children with poor academic performance. Material and Methods: Total of 1483 children studying in 3 CBSE schools, aged between 6 and 12 years were screened. 312 children were found to be performing poor in academics. After simple randomization and further screening procedure 115 children were included in the study. Each child was assessed by interviewing with NIMHANS INDEX OF SpLD. Statistical analysis was done using Epi Info 7 software. Results: The prevalence of poor academic performers was found to be $21.08 \%$. The prevalence of specific learning disorder among children with poor academic performance was found to be $10.43 \%$. Majority of poor academic performers have Specific reading disorder accounts to be $4.35 \%$ and Specific disorder arithmetical skills accounts to be $2.61 \%$, Specific spelling disorder accounts to be $2.61 \%$. And mixed disorders of scholastic skills accounts to be $1.74 \%$.Conclusion: Specific learning disorder in school going children leads to poor performance in academics and school drop outs. Finding out the children with SpLD and early intervention helps to prevent school dropouts.

Keywords: Specific learning disorder, Poor academic performance

Learning is acquisition of new knowledge, skills or attitude. Development of any child starts in early age with learns to understand the spoken language first and then learn to speak. Subsequently during their school years learn to read, write and do arithmetic according to their

\footnotetext{
${ }^{1}$ Assistant Professor, Department of Psychiatry, Gadag Institute of Medical Sciences , Gadag. Karnataka state, Country-India

${ }^{2}$ Assistant Professor Department of Psychiatry, J N Medical college, Belagavi. Karnataka state, Country-India

${ }^{3}$ Post graduate student, Department of Psychiatry, J.N. Medical College, Belagavi. Karnataka state, Country-India

${ }^{4}$ Assisstant Professor, Department of Psychiatry, USM-KLE International Medical Programme, Belagavi.

Karnataka state, Country-India

${ }^{5}$ Post graduate student, Department of Psychiatry, J.N. Medical College, Belagavi. Karnataka state, Country-India

${ }^{6}$ Post graduate student, Department of Psychiatry, J.N. Medical College, Belagavi. Karnataka state, Country-India

*Responding Author
}

Received: December 24, 2016; Revision Received: January 25, 2017; Accepted: February 2, 2017

(C) 2017 Mugali J, Patil S, Gosavi K, Pattanshetti N, Kovvuri S, Deepthi PT; licensee IJIP. This is an Open Access Research distributed under the terms of the Creative Commons Attribution License (www.creativecommons.org/licenses/by/2.0), which permits unrestricted use, distribution, and reproduction in any Medium, provided the original work is properly cited. 


\section{Study of Specific Learning Disorder in Children with Poor Academic Performers}

age and intellectual capacity. Education has major influence on the life any child But for children with disabilities, the quality of schooling they receive is likely to have an even greater and longer lasting impact. ${ }^{1}$ Though education during childhood is a decisive component of human development, not every child thrives in it. $^{2}$

Specific learning disorders include mainly dyslexia, dysgraphia and dyscalculia. SpLD is also a common cause for poor academic performance, but the exact prevalence of SpLD in poor academic performers is not studied. The problems like dyslexia, dysgraphia and dyscalculia make the child to perform poorer in their academics. Children with SpLD go unidentified as they do not have visible problems, simply labeled as "mentally backward" or "not interested in reading" by teachers and parents.

There is wide variation in prevalence rates of SpLD. According to meta-analysis by Dockrell, children aged between 8-11 years on SpLD recorded wide range of prevalence of $3 \%$ to $28 \%$. $^{3}$ The study done by Mogasale V V et al. prevalence of SpLD among primary school children aged 8-11 years from $3^{\text {rd }}$ and $4^{\text {th }}$ standard in Belagavi city was $15.17 \% .{ }^{4}$ Several instances showed children with learning disabilities also had co-morbid psychiatric problem like anxiety disorder (18.68\%). ${ }^{5}$ Another epidemiological study in British school children in the age range of 8-10 year found the prevalence of 'specific reading difficulties', specific arithmetic difficulties and combined 'specific arithmetic-and-reading difficulties to be $3.9 \%, 1.3 \%$ and $2.3 \%$ respectively. Thus, the overall prevalence of SpLD may be around $7.5 \%$. ${ }^{6}$ Shah et al in their review article on specific learning disorders have described the prevalence of SpLD to be in the range of $2-10 \%$ and 2-4 times more frequent in boys. ${ }^{7,8}$

\section{METHODOLOGY}

\section{Source of data}

Children of age group between 6 and 12 years studying in CBSE (Central Board of Secondary Education) schools in Belagavi city with poor academic performance.

\section{Method of collection of data}

Study Design: Cross sectional study, Study Duration: 1 year , Sample size: 115

\section{Inclusion criteria}

Students aged between 6 and 12 years from CBSE schools, Both genders, Students scoring Grade 'C' and below in final examination.

\section{Exclusion criteria}

Students with visual, hearing impairment and other physical disabilities. Students suffering from acute and preexisting chronic medical disorders. Students whose IQ (Intelligence Quotient) is below 70 . 


\section{Tools used}

MINI-KID Questionnaire, Child Behavioral Check List (CBCL), NIMHANS Index for Specific Learning Disorders, Temperament of children was assessed by Temperament Assessment Scale. The final diagnosis was made using ICD 10 DCR criteria.

\section{RESULTS}

Figure 1: Study flowchart

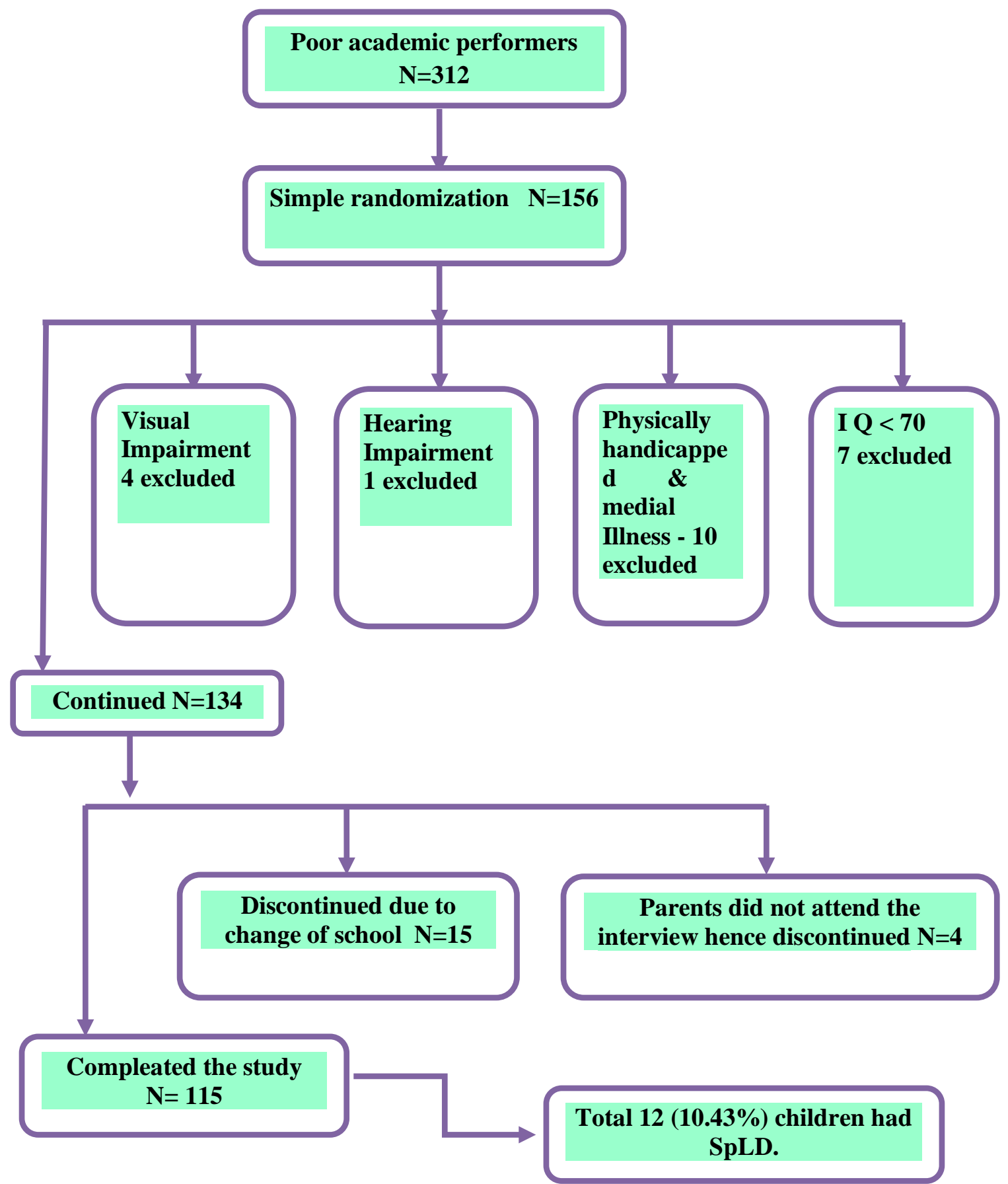

(c) The International Journal of Indian Psychology, ISSN 2348-5396 (e)| ISSN: 2349-3429 (p) | 154 
Study of Specific Learning Disorder in Children with Poor Academic Performers

Table no 1: Prevalence of specific learning disorder. $\mathrm{N}=115$

\begin{tabular}{|l|l|l|}
\hline Variables & Total number of children \\
\hline $\begin{array}{l}\text { Specific learning } \\
\text { disorder }\end{array}$ & Yes & $08(66.67 \%)$ \\
\cline { 2 - 3 } & No & $04(33.33 \%)$ \\
\hline
\end{tabular}

Figure no 2: Specific learning disorder among children with poor academic performance.

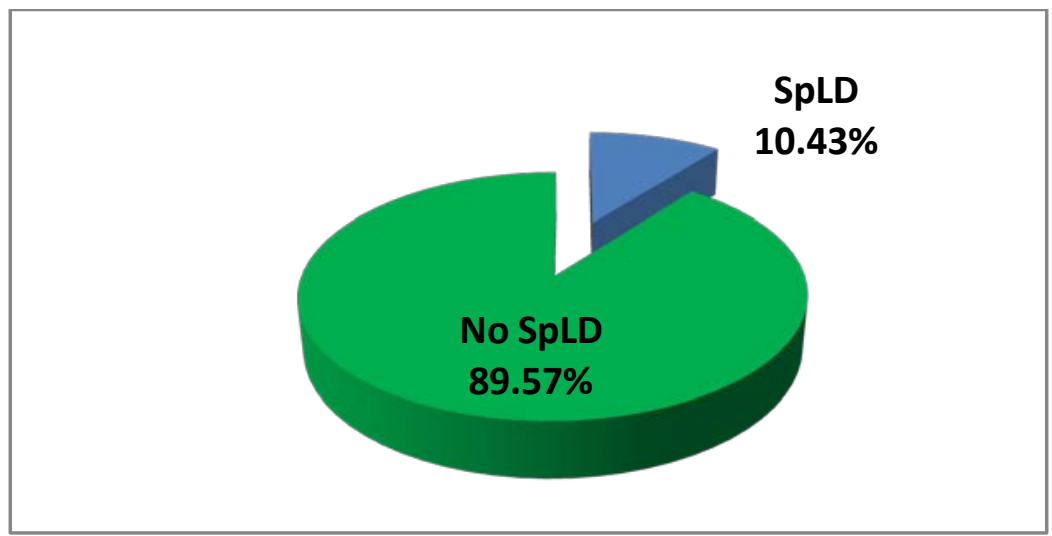

Table no 1 and fig no $1 \& 2$ shows that prevalence of the specific learning disorder among children with poor academic performance. With reference from study flow chart total 115 children completed the study, 12 children were with specific learning disorder that accounts to be $10.43 \%$.

Table no 2: Distribution of Specific learning disorder among each gender $N=12$

\begin{tabular}{|l|l|l|}
\hline \multicolumn{2}{|l|}{ Variables } & Specific learning disorder \\
\hline \multirow{2}{*}{ Gender } & Boys & $08(66.67 \%)$ \\
\cline { 2 - 3 } & Girls & $04(33.33 \%)$ \\
\hline
\end{tabular}

Table no 2 shows that specific learning disorder among children with poor academic performance. Out of 12 children with SpLD, 08 (66.67\%) were boys and 04 (33.33\%) were girls.

Table no 3: Distribution of individual disorders in specific learning disorder category.

\begin{tabular}{|l|l|}
\hline Types of Specific learning disorder & Percentage \\
\hline Specific reading disorder & $4.35 \%$ \\
\hline Specific disorder arithmetical skills & $2.61 \%$ \\
\hline Specific spelling disorder & $2.61 \%$ \\
\hline Mixed disorders of scholastic skills & $1.74 \%$ \\
\hline
\end{tabular}

(c) The International Journal of Indian Psychology, ISSN 2348-5396 (e)| ISSN: 2349-3429 (p) | 155 
Figure No 3: Distribution of Study Participants According to Individual Category of Specific Learning Disorder.

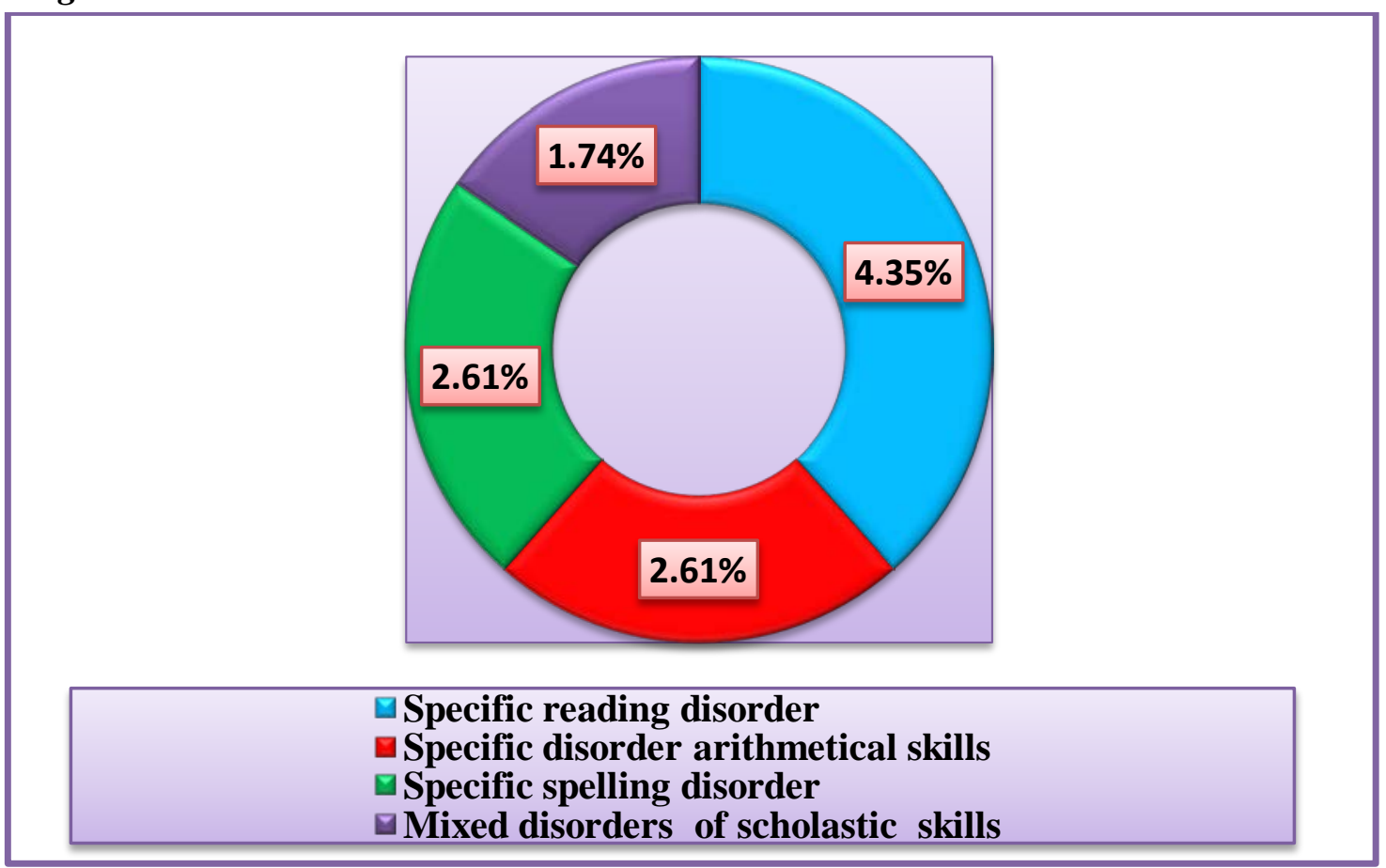

Table no 3 and fig no 3 shows that distribution of study participants according to individual disorder in specific learning disorder. $4.35 \%, 2.61 \%, 2.61 \%$ and $1.74 \%$ of study participants were having specific reading disorder, specific disorder in arithmetical skills specific spelling disorder and mixed disorders of scholastic skills

\section{DISCUSSION}

As already shown in the study flow chart, about systematic way of considering exclusion and inclusion criteria and application of required scales. Out of 1483 children between 6-1 years age group 312 were performing poor in their academics. Total 115 children were completed the study. $10.43 \%$ of the children with poor academic performance were having SpLD. (prevalence of SpLD ).

Among participants of the specific learning disorder category, Specific Reading Disorder accounted for 5 (4.35\%) followed by Specific Disorder Arithmetical skills, Specific Spelling Disorder and Mixed Disorders of Scholastic Skills with prevalence rates of 3 (2.61\%), 3 (2.61\%), and 2 (1.74\%) respectively. There is literature available on individual disorders. In one of the studies from India, prevalence rates of dyslexia, dysgraphia and dyscalculia were 2-18\%, $3-14 \%$ and $3-6 \%$ respectively. ${ }^{4}$

Our findings were more or less similar to the results of above mentioned studies. This study actually enhances and adds the data of prevalence/nature of SpLD among children with poor academic performance. There were very few studies in India in this aspect.

(C) The International Journal of Indian Psychology, ISSN 2348-5396 (e)| ISSN: 2349-3429 (p) | 156 


\section{Study of Specific Learning Disorder in Children with Poor Academic Performers}

\section{CONCLUSION}

Specific learning disorder in school going children leads to poor performance in academics and school drop outs. Finding out the children with SpLD and early intervention helps to prevent school dropout and school refusal.

\section{Acknowledgments}

The author appreciates all those who participated in the study and helped to facilitate the research process.

Conflict of Interests: The author declared no conflict of interests.

\section{REFERENCES}

1. Howlin P. Special educational treatment. In: Rutter M, Taylore E, editors. Child and adolescent psychiatry. 4th ed. UK: Blackwell publishing company; 2002. p. 1128-47.

2. Rutter M. Family and school influences on behavioral development. Journal of child psychology, psychiatry and Allied disciplines. 1985; 26: 349-68.

3. Dockell J, JM. Children`s learning difficulties. Cambridge: Blackwell 1993.p.154-6

4. Mogasale VV, Patil VD, Patil NM, Mogasale V. Prevalence of specific learning disabilities among primary school children in a South Indian City. Indian J Pediatr. 2012;79:482-97

5. Angela I. Frank-Briggs, E. A. D. Alikor. Anxiety Disorder amongst Secondary School Children in an Urban City in Nigeria. Int J Biomed Sci. 2010;6:246-51.

6. Lewis C, Hitch GJ, Walker P. The prevalence of specific arithmetic difficulties and specific reading difficulties in 9 to 10 year old boys and girls. Journal of Child Psychology and Psychiatry 35 (2), 283-292.

7. Ruth S. Shalev, MD Developmental Dyscalculia. Journal of Child Neurology, 2004, Vol. 19, No. 10, 765- 771

8. Shalev RS, Auerbach J, Manor O, Gross-Tsur V: Developmental dyscalculia: prevalence and prognosis. Child Adolesc Psychiatry 2000, 9 Suppl 2:II58-64

How to cite this article: Mugali J, Patil S, Gosavi K, Pattanshetti N, Kovvuri S, Deepthi PT (2017), Study of Specific Learning Disorder in Children with Poor Academic Performers, International Journal of Indian Psychology, Volume 4, Issue 2, No. 87, ISSN:2348-5396 (e), ISSN:2349-3429 (p), DIP:18.01.060/20170402, ISBN:978-1-365-71287-6 